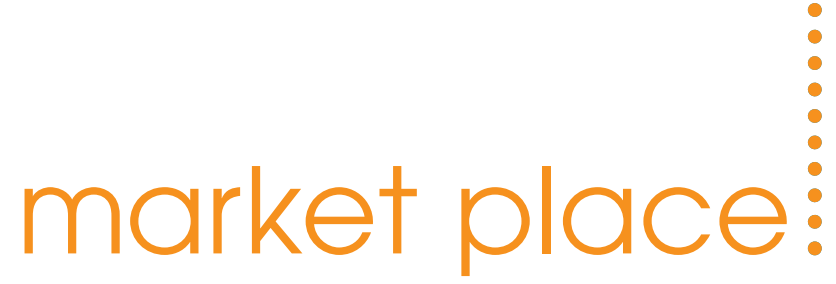

Market place is provided as a service to readers using text and images from the manufacturer, supplier or distributor and does not imply endorsement by Vital. Normal and prudent research should be exercised before purchase or use of any product mentioned.

\section{Stain no more}

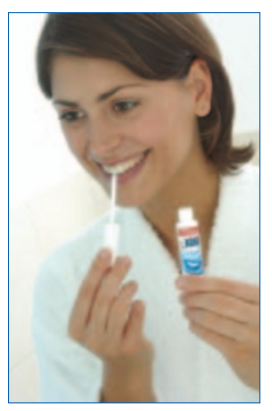

Patients are always looking for ways to combat stains caused by red wine, coffee and tobacco. If they are planning or have just undertaken a clinical whitening procedure, they might like to try Back2White, a stain remover created by Dexcel Dental which works in complement to the treatment.

Back2White is a clear liquid which is applied directly on to the tooth surface with a soft brush applicator, included in the pack. As it dissolves, a peroxide bleaching agent is gradually released. Colourless, it is applied up to twice a day for a fortnight, and less often thereafter, to help maintain the colour of the teeth and the effects of the clinical whitening procedure. Dexcel Dental say that as a highly effective and cost efficient tooth stain remover, Back2White has performed well in clinical trials, with significant improvements in tooth colour after only two weeks of use.

For more details call Dexcel Dental on 08000132333.

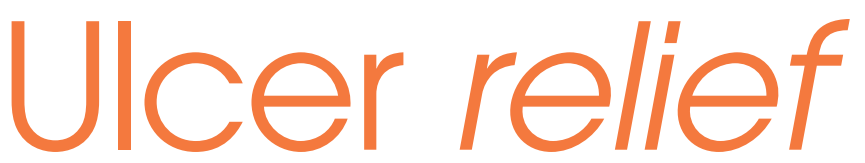

Mouth ulcers are a common irritation which can take time to heal. They can be brought on as a result of stress, irritants, bacterial, viral or fungal infections, discoid herpes or erythematosas. Aiming to combine pain relief and preven-

tative measures, Oraldent has developed Gengigel.

Gengigel works to limit the soreness and discomfort caused by mouth ulcers and accelerates the healing process while reducing the likelihood of re-infection. It contains the ingredient hyaluronan which helps control inflammation and regulates pressure and tissue lubrication. Oraldent is confident that this easy-to-use gel will provide mouth ulcer sufferers with long-term relief.

For further information call Oraldent on 01480862080.

\section{Fun, flexible study}

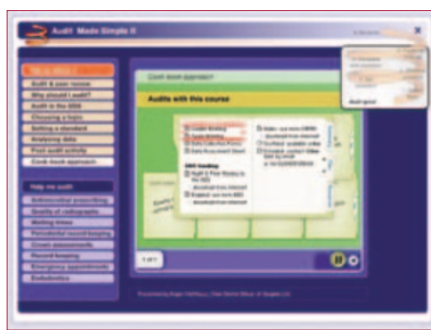

DNNET from Smile-on is a fun and flexible way for dental nurses to study for the National Certificate or NVQ in Oral Health Care Dental Nursing. Developed in association with teaching staff at Eastman Dental Hospital, the programme is highly interactive with multimedia presentations including audio, video and graphics. It also features self-testing activities with automated answer correction facilities.

Users of DNNET are automatically enrolled on the Eastman Distance Learning programme, satisfying the regulatory requirement to be in training, and the package provides guidance on building a 'portfolio of evidence' that will include case studies, projects and written reports. A full range of topics are covered, from endodontics to equality and diversity, and from processing radiographs to patient assessment.

For further information visit www.smile-on.com

\section{A profitable practice}

If you want to improve profits in your practice, Henry Schein has developed a programme that involves the whole dental team.

Recommending and selling oral hygiene products can generate regular additional income for the practice, and patients benefit from using a range of leading products. Henry Schein, in partnership with Colgate and Philips, will provide training and support for the whole team, at your practice, in every aspect of managing successful practice retailing. They will help you with product merchandising, provide posters and prescription pads and give expert advice on staff motivation and incentives.

For further information on Henry Schein's Practice Retailing Programme, call 08700102043.

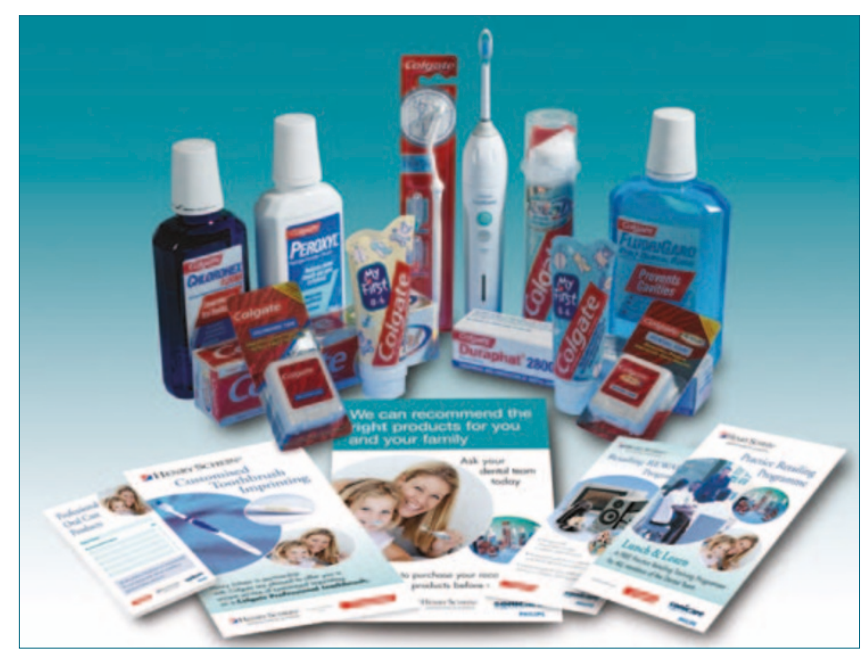

